\title{
Representación política en los países andinos: Crisis y recuperaciones ${ }^{+}$
}

\author{
JORGE ARAGÓN* \\ Pontificia Universidad Católica del Perú \\ jaragon@pucp.pe \\ https://doi.org/10.18800/rcpg.201601.005
}

\section{Resumen}

El análisis de la situación política de los países andinos y de sus actuales democracias suele hacer mención a las dificultades y deficiencias alrededor de la representación política de sus ciudadanos. En varios sentidos, diera incluso la impresión de que los actuales países andinos sufren una crisis crónica de representación política. El análisis de la evidencia empírica que por lo general se utiliza para dar cuenta del estado de la representación política dentro de los países andinos revela, sin embargo, que existen tanto momentos de deterioro como de cierta recuperación en las percepciones y evaluaciones de los ciudadanos en relación con el funcionamiento de la democracia, de las instituciones representativas, de los mecanismos y canales de representación, de los gobiernos y las autoridades elegidas, etcétera. Dar cuenta de la naturaleza y dinámica de estos cambios es el principal objetivo de este artículo. En el camino no deja de llamar la atención que algunos de estos procesos, que bien pueden ser definidos como de recuperación de la representación política, sucedan sobre todo en Venezuela, Ecuador y Bolivia.

Palabras clave: Representación política, democracia, países andinos, opinión pública, Perú.

\section{Political representation in the Andean countries: Crisis and recovery.}

\begin{abstract}
The analysis of the political situation of the Andean countries and their current democracies usually makes mention of the difficulties and deficiencies around the political representation of their citizens. In many ways, it would even give the impression that the present andean countries suffer from a chronic crisis of political representation. The analysis of the empirical evidence that is generally used to account for the state of political representation within the andean countries reveals, however, that there are both moments of deterioration and a certain recovery in the perceptions and evaluations of citizens in relation to the functioning of democracy, representative institutions, mechanisms and channels of representation, governments and elected officials, and so on. Realizing the nature and dynamics of these changes is the main

* Docente del Departamento Académico de Ciencias Sociales. Coordinador de la Especialidad de Ciencia Política y Gobierno de la Facultad de Ciencias Sociales de la PUCP.

+ Recibido el 11 de abril de 2016; aceptado el 28 de septiembre de 2016.
\end{abstract}


objective of this article. Along the way, it is not surprising that some of these processes, which may well be defined as the recovery of political representation, happen mainly in Venezuela, Ecuador and Bolivia.

Key words: Political representation, democracy, Andean countries, Public opinion, Peru. 


\section{INTRODUCCIÓN}

De una u otra forma, el análisis de la situación política de los países andinos y de sus actuales democracias suele incluir alguna mención a los problemas y deficiencias de la representación política. Es más, hasta hace relativamente muy poco existía un amplio consenso en torno a que la magnitud de estas deficiencias justificaba hablar de una crisis generalizada, severa $y$, muy probablemente, crónica de la representación política en esta parte del mundo. Por lo general, la evidencia que se presentaba a modo de sustento empírico era resultado de diferentes estudios de opinión pública que mostraban percepciones y evaluaciones muy negativas de los ciudadanos latinoamericanos en relación con el funcionamiento de la democracia, de las instituciones representativas, de los mecanismos y canales de representación, de los gobiernos y las autoridades elegidas, entre otros.

Esta situación no dejaba de tener algo de paradójica porque esta percepción generalizada de falta de representación política en la gran mayoría de países de esta región se daba al mismo tiempo que ocurría un conjunto de reformas que habían expandido de manera significativa las oportunidades de participación política y eliminado barreras que restringían el acceso a nuevas fuerzas políticas (Mainwaring 2008, Negretto 2009, Pachano 2012). Es más, en relación con esta naturaleza paradójica del funcionamiento de la política en los países andinos, Mainwaring (2008: 380) sugería que la expansión de la ciudadanía política no habría hecho sino reforzar la sensación de una crisis de representación entre los ciudadanos.

En algunos otros casos, se planteaba simplemente que en el caso de los países latinoamericanos lo que existía era una continua y pronunciada brecha dentro de sus regímenes democráticos entre los miembros del Congreso - la institución representativa del Gobierno por excelencia- y la gran mayoría de ciudadanos pobres; y que esta brecha llegaba a su mayor magnitud sobre todo en el tiempo que transcurría entre dos procesos electorales (Taylor-Robinson 2010). Vale la pena destacar que en este tipo de argumentación la falta de una representación política efectiva se debía básicamente a que los pobres carecen de los medios necesarios para monitorear las decisiones de las autoridades elegidas y para sancionarlas cuando sus políticas se alejen demasiado de sus propias preferencias (Taylor-Robinson 2010: 2-3).

Frente a esta situación, es posible hacerse un conjunto de preguntas que creemos son particularmente útiles para entender mejor cuál es la situación y cuáles son las perspectivas de los actuales regímenes democráticos en los países andinos. Para comenzar, habría que preguntarse cuál ha sido o es la naturaleza 
de esta crisis de la representación política en estos países y qué alternativas habría o serían viables para intentar remediarla. De manera más específica, es necesario preguntarse también qué cambios se han dado en relación con esta crisis y hasta qué punto es posible seguir sosteniendo que la representación política continúa estando en crisis en estos países. Plantearse este tipo de preguntas, en el marco de una perspectiva que compare lo que sucede en los diferentes países que componen la región andina (Bolivia, Ecuador, Colombia, Perú y Venezuela), debería, a su vez, ayudarnos también a entender mejor lo que viene sucediendo con la democracia y la representación política en el Perú.

Intentar responder estas preguntas obliga, en primer lugar, a discutir el concepto mismo de representación política y a revisar la literatura más relevante que se ha producido para el caso de los países andinos. Finalmente, y dado que en mucha de esta literatura existe un fuerte desbalance entre teoría e investigación empírica, un esfuerzo de este tipo obliga a tener en cuenta alguna información empírica que permita poner a prueba las ideas que circulan sobre la manera cómo vienen funcionando la política y la democracia en estos países.

Para concluir esta introducción, es importante destacar que los regímenes democráticos contemporáneos están intrínsecamente asociados a la existencia de gobiernos representativos (Sartori 1999). Que buena parte de su naturaleza y dinámica depende del tipo de relación o relaciones que se establecen entre quienes son gobernados (los representados) y quienes gobiernan (los representantes); ${ }^{1}$ es decir, en el tipo de vínculo a partir del cual los representados delegan la capacidad de tomar decisiones políticas en sus representantes. Asimismo, habría que destacar que no existe régimen democrático alguno en el mundo — incluyendo, por supuesto, su dimensión representativa- que no esté bajo sospecha de no ser lo que debería o podría ser como gobierno del pueblo o la mayoría (Przeworski 2010, O’Donnell 2007). Esto último debería ser de mucha utilidad para poder distinguir lo particular y lo no tan particular en relación con la situación de los países andinos.

\section{REPRESENTACIÓN POLÍTICA: DEFINICIONES Y DEBATES}

Lo primero que se puede mencionar sobre el concepto representación politica es que estamos frente a una idea ampliamente usada entre quienes se dedican al análisis de la política y de la democracia, particularmente compleja y no

\footnotetext{
1 No está de más tener en cuenta que si bien todo régimen democrático es o debería ser representativo, no toda representación política, efectiva o no, es necesariamente democrática.
} 
con pocas tensiones y ambigüedades. ${ }^{2}$ Ahora bien, a pesar de su complejidad y de todas las discusiones que giran en torno a ella, es posible identificar lo que puede ser considerado como un núcleo duro o una definición básica de lo que está en juego cuando se habla de representación política. En este sentido, se puede afirmar que este concepto hace alusión a la conexión que existe o debería existir entre los intereses y las preferencias de los representados (ciudadanos) y las decisiones y posiciones de quienes los representan (gobernantes); bajo el supuesto que los representantes tratan en todo momento de actuar de acuerdo al mejor interés de la gente que están representando (Pitkin 1985, Manin et al. 1999, Luna 2006). A continuación, partiendo de lo propuesto por diferentes autores, se propone y justifica un núcleo básico y compartido en torno al concepto representación política. Se hace mención también a algunos cambios que habrían modificado de manera significativa el contexto en el que se da la relación entre gobernantes y gobernados en la actualidad. Luego se presentan y discuten algunos de los debates y discusiones clave sobre la naturaleza y la dinámica de la representación política.

\section{1. ¿De qué hablamos cuando hablamos de representación política?}

Desde una perspectiva teórica, muchos trabajos en torno a la representación política realmente existente en regímenes democráticos dejan varias preguntas sin responder. ${ }^{3}$ En alguna medida esto se explica porque, con cierta frecuencia, el interés de los autores no es la representación política en sí misma sino algunas de sus condiciones (Manin et al. 1999) o de sus consecuencias (PNUD 2010). Se explica también porque este concepto tiene una larga historia, no con pocas ambigüedades, y porque es particularmente complejo (Sartori 1999, Manin et al. 1999, Pitkin 1985). Con relación a su complejidad, se ha afirmado que no podía ser de otro modo, dado los varios y diversos aspectos de la vida política y social que se encuentran vinculados a la representación política (Pitkin 1985: 252).

No obstante esta complejidad, es posible encontrar un conjunto de elementos compartidos entre quienes abordan el significado de la representación política. En esta dirección, Manin et al. (1999), siguiendo lo planteado por Pitkin

\footnotetext{
2 Un aspecto adicional sobre la literatura sobre representación política que se mencionará más de una vez en este trabajo es la marcada ausencia de trabajos que hayan incorporado en su estudio una dimensión empírica y la ausencia de esfuerzos por desarrollar una estrategia de operacionalización de la representación política que puede ser considerada mínimamente válida y confiable.

3 Esto es especialmente significativo cuando, por ejemplo, en el contexto de uno o varios países se vuelve tan frecuente hablar de una crisis o falta de representación política que se descuidan el alcance y los límites de las definiciones conceptuales que se manejan.
} 
(1985), definen la representación política como el actuar en el mejor interés de la gente a la que se está representando. De manera similar, Luna (2006) vincula el concepto de representación política con los vínculos que se establecen cuando los representantes (principales) delegan la capacidad de formular decisiones políticas en sus representantes (agentes). Por lo tanto, lo primero que podría quedar fuera de duda es que la representación política alude a la conexión que existe entre los intereses y preferencias de los ciudadanos, y las decisiones y posiciones de sus representantes — que son a la vez los gobernantes—. ${ }^{4}$

Algo parecido sucede en relación con lo que se considera son los procedimientos y arreglos institucionales mínimamente necesarios para que sea posible la representación política. En este sentido, en el contexto de las sociedades actuales, es ampliamente aceptado que la representación política en estos casos pasa por la selección de los gobernantes a través de elecciones periódicas; por el derecho de los ciudadanos a discutir y criticar lo que hace el Gobierno, sin dejar por ello de aceptar sus decisiones; y por el derecho de los ciudadanos a esperar que el Gobierno responda a sus demandas (Manin et al. 1999).

Un tema que no debería quedar fuera de consideración es el relacionado con los cambios o transformaciones que han ocurrido en las sociedades contemporáneas y que, definitivamente, han modificado a su vez los contextos sociales y políticos en los que se plantea la posibilidad de una representación de los gobernados por parte de los gobernantes. Dicho de otra manera, es importante también considerar qué características particulares tiene la forma como opera la representación política en los regímenes políticos contemporáneos. Esto debería ser particularmente relevante para evaluar qué aspectos de los paradigmas teóricos tradicionalmente utilizados necesitan ser reconsiderados y revisados.

En esta dirección, Manin (1992) plantea que lo que se ha generado en los últimos años es una nueva forma de representación política: la democracia de lo público. Según este autor, los principios de la democracia no han cambiado, pero sí lo han hecho el contexto y la manera en que ellos operan. De manera específica, se han producido importantes transformaciones en las preferencias electorales de los ciudadanos y se han generado canales de comunicación directa entre candidatos y electores. A su vez, la personalidad y la imagen de

\footnotetext{
4 Posteriormente, en el año 1980, por Ley 23230, el Congreso de la República delegó en el Poder Ejecutivo la facultad de derogar o modificar la legislación expedida a partir del 3 de octubre de 1968, entre otras materias, sobre la reorganización, competencia y funcionamiento de los ministerios y empresas públicas. Mediante el decreto legislativo 098, se establece la Ley de la Empresa Nacional de Puertos del Perú S.A.
} 
los candidatos y políticos han adquirido una centralidad que antes no poseían. No obstante, va quedando claro también que estas imágenes en torno a las características personales de candidatos y políticos no carecen de contenido político.

Adicionalmente, según Manin (1992), no es la primera vez en la historia política contemporánea que se escucha hablar de una crisis de la representación política. A finales del siglo XIX e inicios del XX se agotó y entró en crisis lo que hasta ese momento era el típico lazo representativo entre gobernantes y gobernados: el parlamentarismo. De hecho, la democracia de partidos (de masas) reemplazó al parlamentarismo como gobierno representativo y dio solución a lo que se consideraba como una crisis de la representación política. A partir de esta experiencia previa, este autor sugiere que lo que estamos viendo hoy no es una crisis de la representación política en sí misma sino el surgimiento de una nueva y tercera forma de gobierno representativo.

De manera consistente con la afirmación previa, Manin (1992) enumera cuatro principios que estarían contenidos en los gobiernos representativos: (1) gobernantes elegidos por los gobernados, (2) gobernantes conservando cierto margen de independencia o de autonomía en relación con los gobernados, (3) una opinión pública que puede expresarse más allá del control de los gobernantes y (4) decisiones colectivas que se derivan de la deliberación. Estos principios no habrían dejado de estar presentes en la democracia de lo público (la forma de representación política que habría venido a reemplazar a la democracia de partidos), lo que habría cambiado, básicamente, serían las condiciones en las que ellos estarían operando en la actualidad.

Cuáles serían algunos de los cambios más significativos que estarían, a su vez, explicando las transformaciones de las representaciones representativas. Varios de ellos estarían vinculados a un conjunto de cambios a nivel del comportamiento electoral. Para comenzar, las preferencias electorales pueden variar significativamente de una elección a otra, aun cuando las características sociales, económicas y culturales de los electores permanezcan casi idénticas durante el periodo considerado. De la misma manera, una gran parte de los electores en estos tiempos votan de manera diferente de una elección a otra porque lo que más pesa o lo que más importa ahora es la personalidad de los candidatos a expensas del partido o del programa. A su vez, esta "personalización» de la política se vincula al hecho de que la radio y la televisión se hayan convertido en los principales medios de comunicación - lo cual ahora hace posible que los electores se relacionen de una manera directa con los candidatos y que estos puedan hacerse conocidos sin depender de la mediación de una organización 
política- y al hecho de que las tareas de gobierno se hayan acrecentado y complejizado de manera muy significativa en los últimos tiempos — lo cual implica que los programas partidarios no puedan contener de antemano las medidas específicas que vaya tomando un Gobierno y que sea razonable elegir a los candidatos según su capacidad o actitud para tomar decisiones-.

Con relación a la manera como se desarrolla la opinión pública, un aspecto a considerar es el desacople que se ha producido entre medios de comunicación y organizaciones partidarias. De este modo, es muy frecuente que los individuos formen sus propias opiniones bebiendo de las mismas fuentes, que exista cierta homogeneización en relación a la percepción de los objetos políticos o públicos y que los votantes deliberen antes de emitir su voto usando una serie de imágenes y argumentos que no necesariamente van a ser los mismos en la próxima elección. Finalmente, se reconoce que actualmente en muchas sociedades occidentales ninguna división social, económica o cultural es mucho más importante que las demás y, por lo tanto, se imponga a priori como una división o clivaje primordial.

A modo de síntesis, Manin (1992: 35) sugiere que lo que se está esbozando es una nueva forma de representación de política. En esta nueva forma, suele suceder que son los políticos quienes toman la iniciativa de proponer un principio de escisión y, por consiguiente, buscan descubrir algunas divisiones en el electorado y llevarlas a la escena pública. Por su parte, los electores delegan o no su confianza en algunos de estos políticos, que aparecen como portavoces de alguna división importante dentro del electorado.

Ahora bien, todos estos cambios no tendrían que ser vistos como una pérdida en relación con la manera en que se estructuraba la representación política en la democracia de masas. Tal como lo sugiere Manin (1992: 36), si bien es cierto que hoy en día los gobernantes son elegidos en base a lo que se denomina «imágenes» (tanto de los partidos como de las organizaciones políticas), también lo es que ellas no están vacías de contenido político. Estas imágenes, con todas sus limitaciones — pueden ser simplificadas y esquemáticas-, constituyen representaciones políticas. Es más, estas representaciones esquemáticas pueden ser particularmente relevantes para un gran número de electores que no tienen una cultura suficiente como para captar en detalle las medidas técnicas que les son propuestas y las razones que pueden justificarlas, y que operen en general como una simplificación que reduce los costos de la información. 


\subsection{Debates en torno a la representación política}

La investigación en torno a la representación política también está marcada por una serie de debates mucho más abiertos. Para comenzar, es evidente que las diferentes posiciones en torno a lo que está en juego en la representación política van variando dependiendo del grado de complejidad con el que se quiera trabajar. De igual manera, es claro que algunos de los temas más intensamente discutidos son (a) las atribuciones, habilidades y capacidades de los representantes y de los representados, (b) la naturaleza de las cuestiones que son y que pueden ser representadas políticamente, (c) los procesos a través de los cuales se establecen las demandas y los intereses a ser representados y (d) los mecanismos para evaluar la calidad de la representación política existente.

Con relación a algunos de estos temas, Pitkin (1985) sostiene que el concepto de representación política implica que el representante actúe teniendo en cuenta el interés de los representados. Sin embargo, reconoce que esta conceptualización de la representación política no debe pasar por alto la posibilidad de que surjan conflictos entre representantes y representados; en gran medida porque el representante tiene la capacidad y la posibilidad de desplegar acciones y juicios independientes. No obstante, asume que, en caso de conflicto, el representante debería tener una explicación de por qué sus deseos o preferencias no están de acuerdo con el interés de sus representados; asume también que el representante no debería hallarse con demasiada frecuencia a contracorriente de los deseos de sus representados.

Adicionalmente, según Pitkin (1985: 239), no debería pasarse por alto la existencia de un conjunto de características propias de la vida política que implican una serie de desafíos alrededor de los vínculos que se establecen entre representante y representados. Y que, en conjunto, podrían explicar el por qué a veces es tan difícil que actores y grupos sociales se sientan efectivamente representados políticamente. En esta línea, un representante político por ejemplo el típico congresista o parlamentario - ha sido elegido por un conjunto diverso de personas y eso abre una serie de preguntas en relación con los intereses y voluntades frente a los cuales el representante debería ser sensible, y en relación con la naturaleza del grupo social frente al cual debe justificar sus decisiones. De igual modo, los desafíos vinculados a la representación se complican aún más si se tiene en cuenta la volatilidad, maleabilidad y la apatía del electorado; y el hecho de que la efectividad de la representación política depende en parte de la existencia o no de diferentes mecanismos para que los representados expresen sus demandas y deseos. No menos relevante es también el hecho de que los representantes trabajan con otros representantes 
en contextos institucionalizados y cumpliendo diferentes tareas de gobierno (Pitkin 1985: 257).

Por su parte, Powell (2004) plantea que lo particular de la representación política en un régimen democrático es el desarrollo de un conjunto de instituciones que facilitan y hacen posible la correspondencia entre las preferencias de los representados y las decisiones de los representantes. Por lo tanto, una parte importante de la representación política se juega en los procesos electorales donde los ciudadanos elijen (delegan el poder para elaborar las políticas públicas) a sus autoridades. En este sentido, es posible sostener que una institución esencial e irremplazable para la representación política es la existencia de elecciones libres y competitivas. Sin embargo, la representación política no se agota en el proceso electoral. Buena parte de ella se juega también en la medida en que las preferencias de los ciudadanos se corresponden con las posiciones y el comportamiento de los representantes. No obstante, y tal como lo han demostrado diferentes estudios de opinión pública, los ciudadanos tienden a tener preferencias políticas débilmente estructuradas, incluso en sociedades desarrolladas y con discursos partidarios importantes. Esto definitivamente actúa como un obstáculo para la representación política; sobre todo en contextos donde los partidos políticos existentes tienen dificultades para tener, frente a los ojos de los ciudadanos y electores, paquetes de políticas públicas con las cuales ellos estarían particularmente comprometidos.

A su vez, Manin et al. (1999) proveen una interesante discusión en torno a las maneras a través de las cuales la representación política puede hacerse efectiva. Todas ellas vinculadas a la representación de los intereses de los ciudadanos. Para comenzar, existe un tipo de situación que facilita en gran medida el que un gobierno sea representativo. Se trata de aquellos casos cuando el curso de acción de un gobierno es claramente el mejor para todos los ciudadanos. En estos casos, los gobiernos representan efectivamente los intereses individuales de los ciudadanos porque el «interés común» no es otra cosa que la suma de diferentes intereses. En segundo lugar, es posible que un gobierno sea representativo aun en el caso en el que se trata de situaciones del tipo «dilema del prisionero" para los ciudadanos individuales. En estos casos, los gobiernos representan o defienden un interés colectivo que no es precisamente el interés de los ciudadanos individuales. No obstante, a la larga ese interés colectivo termina siendo beneficioso para el conjunto de ciudadanos. Finalmente, en situaciones donde claramente existe un conflicto de intereses y las decisiones del gobierno implicarán que algunos ganen y otros pierdan, es posible que ese gobierno sea representativo. En este sentido, un gobierno será representativo 
si actúa de acuerdo a las preferencias de la mayoría que lo eligió o si actúa de acuerdo a los intereses de cualquier mayoría (el gobierno no es representativo si actúa de acuerdo al interés de una minoría).

Asimismo, Manin et al. (1999) sugieren la existencia de dos momentos clave para la representación política. Uno tiene que ver con la capacidad de los gobiernos para responder en el día a día a las preferencias que les son señaladas por los ciudadanos. El otro está más bien vinculado a la medida en que las políticas del gobierno responden a los compromisos adquiridos durante el último proceso electoral (el mandato electoral). Finalmente, se señala que, a la fecha, la evidencia empírica disponible parece indicar dos patrones más o menos claros. En primer lugar, que con frecuencia los gobiernos hacen lo que la gente dice sobre qué es lo que ellos quieren que haga el gobierno; aunque es mucho menos claro qué sucede primero. En segundo lugar, porque los ciudadanos no suelen poseer la información suficiente y necesaria para instruir al gobierno sobre lo que debe hacer y para juzgar lo que ha venido haciendo (Manin et al. 1999: 23).

Por su parte, Mainwaring et al. (2006) platean que la representación política o democrática implica el establecimiento de una relación Principal-Agente, en donde el Principal (votantes y ciudadanos) elige y autoriza al Agente (políticos, partidos y legislaturas) para actuar en su representación. No desconocen que en toda relación Principal-Agente, el Agente adquiere cierta autonomía y que, por lo tanto, el problema con la representación democrática es siempre la dificultad para limitar esa autonomía y promover algún tipo de «respuesta» (responsiveness) de parte de los políticos y partidos en relación con el interés de los ciudadanos. No desconocen tampoco que estos niveles de autonomía tienden a intensificarse en aquellos casos donde existen profundas asimetrías entre los electores y los políticos (por ejemplo, en relación con niveles de educación o información), donde no es claro cuáles son las preferencias que los electores y los ciudadanos están transmitiendo a sus representantes; donde las elecciones no son frecuentes y en donde no es fácil sancionar, sino hasta las próximas elecciones, a los agentes que no actúan de manera representativa.

Si bien estos autores reconocen que la representación o convergencia programática es un ingrediente importante de la representación democrática, estos autores asumen, al igual que Kitschelt (2000), que la representación política no tiene que ser necesariamente programática (por ejemplo, es perfectamente posible que se originen formas de representación política de naturaleza clientelar). Finalmente, sobre esta representación programática, estos autores presuponen que en un país donde los ciudadanos estén profundamente 
insatisfechos con la representación democrática, la convergencia programática debe de ser débil. Por el contrario, si la representación programática es fuerte, es decir, si los representantes y los representados convergen en sus preferencias ideológicas o sus posiciones programáticas, es mucho más probable que los representados estén satisfechos con los partidos y los políticos.

En relación con otras formas de definir la representación política, estos autores plantean que es muy difícil establecer, desde afuera, si los representantes están actuando de acuerdo a los intereses de los representados. Esto tiene profundas consecuencias en relación con cómo medir la representación política. En este sentido, diera la impresión que existe mucho mayor sustento para hablar de una crisis de representación política en aquellos casos en los cuales los ciudadanos no creen que los representantes estén actuando en nombre de los representados o de un bien común.

En las propias palabras de estos autores:

[...] La existencia de una relación de representación democrática no depende de si los representantes están actuando en nombre del público general o de sus electores; por el contrario, la percepción de los ciudadanos de estar adecuadamente representados depende de que ellos crean que los representantes están actuando en nombre de algo que puede ser considerado como un bien común o de los propios intereses de los ciudadanos. Si los ciudadanos no creen que sus representantes están actuando en nombre de sus electores o de alguna visión compartida de bien común, ellos no tienen razón para sentirse adecuadamente representados. Cuando la percepción de no estar siendo representados es extendida y no transitoria, ella constituye una crisis de representación democrática (Mainwaring et al. 2006: 15).

Un ciudadano puede sentirse adecuadamente representado o porque él cree que sus agentes de representación están tratando de sacar adelante algún bien público o porque él cree que ellos están actuando en defensa de sus intereses. Una relación de representación existe cuando los ciudadanos eligen a sus representantes, pero la satisfacción con los representantes depende de la percepción de cuán bien los representantes están desempeñando sus responsabilidades. Los representantes de dos países pueden estarse desempeńándose de la misma manera y obteniendo los mismos resultados en términos de resultados del gobierno; sin embargo, la evaluación de los representados sobre sus representantes puede ser muy diferente en ambos países (Mainwaring et al. 2006: 15).

Resumiendo, una parte considerable de la discusión en torno al concepto de representación política gira en torno a los esfuerzos por identificar las capacidades y las atribuciones tanto de los representados como de los representantes, por establecer la naturaleza de aquellas cuestiones que pueden ser efectivamente representadas, por identificar los principales obstáculos y desafíos para que efectivamente opere la representación política, y por establecer 
a quién le corresponde en última instancia emitir un juicio sobre la calidad y la efectividad de la representación política existente. Con relación a algunos de estos temas, Pitkin (1985) plantea que siempre será un aspecto crítico a tener en cuenta el grado de autonomía de los representantes en relación con los representados. Por su lado, Manin (1992) sostiene que la representación política tiene dos momentos clave: (1) la generación de un mandato electoral y (2) el día a día de las políticas públicas. De igual forma, varios autores han afirmado que la representación política siempre confronta una serie de desafíos, como, por ejemplo, las profundas asimetrías que existen entre los electores y los políticos, la frecuente apatía de los electores y la debilidad «estructural» de las preferencias políticas de los representados (Pitkin 1985, Manin et al. 1999, Powell 2004). Finalmente, Mainwaring (2008) postula que la participación de los representados es clave al momento de establecer y evaluar los niveles existentes de representación política al interior de un régimen democrático.

\section{RePRESENTACión POLÍtica EN LOS PAísES ANDINOS}

Desde fines de los noventa, y no habiendo pasado muchos años del regreso de la democracia a América Latina, se empezó a hablar de una crisis de representación política en esta región. Específicamente, para el caso de la región andina, Mainwaring et al. (2006) afirmaban que la crisis de representación política en estos países se expresa en una profunda insatisfacción con la democracia, los partidos y las legislaturas; es decir, con los principales agentes y los mecanismos de la representación democrática. Y que es esta profunda insatisfacción la que habría generado, en estos países, el surgimiento de outsiders políticos con claros discursos antisistema.

De modo más detallado, estaba perfectamente justificado hablar de una crisis de la representación política en estos casos porque a nivel subjetivo una mayoría de ciudadanos no confiaba ni percibía como legítimos a los agentes responsables de la representación política y porque a nivel del comportamiento político muchos de estos mismos ciudadanos optaban por apoyar a nuevos partidos, por apoyar a candidatos o partidos con una clara orientación antisistema y por cambiar sus preferencias electorales con gran frecuencia o simplemente abstenerse de participar en las elecciones. Es necesario destacar que la casi totalidad de la evidencia empírica analizada por Mainwaring et al. (2006) para los casos de Bolivia, Ecuador, Colombia, Perú y Venezuela venía de resultados de estudios de opinión pública realizados entre 2002 y 2003, y 
de lo que se observaba en procesos electorales llevados a cabo a comienzos del siglo XXI.

Con relación a las principales causas que eran señaladas como responsables de esta situación, se agrupaban en dos grandes grupos. Primero, en un conjunto de cambios estructurales que modificaron radicalmente la matriz socio-política que había existido previamente en los países de América Latina y que, entre otras cosas, conllevaron al desarrollo de una dinámica política altamente personalizada y mucho menos institucionalizada. En segundo lugar, una serie de deficiencias en las gestiones de los Estados que hacían muy difícil que los actuales regímenes democráticos lograran desarrollar un mínimo de identificación con los ciudadanos de a pie.

A continuación se abordan, en un primer momento, los argumentos que componen la visión sobre la aguda y persistente crisis de representación política en los países andinos. Luego, a partir de lo expuesto por Luna (2006), se plantea que el estudio de la naturaleza y la dinámica de la representación política en América Latina no puede pasar por alto los profundos cambios que se han venido dando alrededor de la "oferta» y la «demanda» política en las últimas décadas (la disminución de la capacidad de acción y mediación de los Estados, los problemas de desempeño que suelen caracterizar a la mayoría de gobiernos en la actualidad y que suelen generar problemas de legitimidad política, los cambios en las relaciones entre electores y organizaciones políticas, etcétera). Y que, por lo tanto, la demanda por desarrollar una nueva sociología de la representación política para los países latinoamericanos es bastante razonable.

\subsection{La crisis de representación política en los países andinos}

A inicios de este nuevo siglo diferentes autores sostenían la existencia de una crisis de representación política en América Latina y, de manera particular, en los países andinos (Hagopian 1998, Roberts 2002, Mainwaring et al. 2006, Corral 2010). En general se afirmaba que, en gran medida, esta crisis de la representación política se manifestaba en una profunda insatisfacción con lo que existía como la "oferta» política (Colomer y Escatel 2005). Aún más, no pocos autores señalaban que una de las explicaciones de la estabilidad política de las actuales democracias latinoamericanas radicaba en que ellas no proveían canales efectivos de representación política para los grupos subalternos (Lechner 1998, Huber y Stephens 1999, Weyland 2005).

Junto a este consenso generalizado, había una importante discusión sobre las causas de esta crisis de representación política. Para comenzar, tal como lo 
señala Luna (2006: 15-16), algunos autores apuntaban en la dirección de un conjunto bastante amplio de variables y factores estructurales como causas de esta crisis. Entre los principales factores estructurales vinculados con los déficits de representación política se identificaban (a) el cambio de la matriz sociopolítica que limita la capacidad del Estado para generar bienestar y mediaciones efectivas entre actores sociales; (b) la crisis económica y la exclusión social de amplios sectores que, junto a la ocurrencia de escándalos de corrupción, retroalimenta el descontento; (c) la creciente fragmentación y segmentación de los grupos de interés que impide la articulación de acción colectiva consistente y una articulación estable con el sistema de partidos; (d) la ausencia de espacios para divergencias programáticas significativas entre partidos en combinación con posturas de oposición fuerte que luego se deslegitiman rápidamente en el gobierno, al prometer "cambio» y entregar lo que se percibe como «más de lo mismo»; (e) la introducción de tecnologías audiovisuales que amplifica los procesos de individualización y los mecanismos de marketing político para generar apoyo electoral volátil en base a liderazgos personalistas (Hagopian 1998, Roberts 2002).

Por su parte, Mainwaring (2008) y Mainwaring et al. (2006), en torno a la crisis de representación política en los países andinos (entendida principalmente como la muy baja confianza con la que cuentan los principales agentes de la representación democrática - legislaturas y partidos - y como el descrédito de la actividad política en sí misma), sostenían que las principales causas eran las fallas o deficiencias estatales en relación con la provisión de bienes y servicios públicos. Específicamente, los Estados andinos habían hecho poco o nada para remediar la pobreza, las desigualdades, la corrupción, el delito y la mala educación pública. Los ciudadanos esperaban que sus representantes elegidos resuelvan estos problemas, o al menos que tomen medidas encaminadas en esa dirección (Mainwaring 2008). Por el contrario, los factores institucionales no parecían ser los responsables primarios de dichas crisis.

De modo similar, cuando Corral (2010) analizaba la confianza en los partidos políticos en los veintidós países de América Latina que se incluyeron en el Barómetro de las Américas del LAPOP (Latin American Public Opinion Project) en 2008, llegaba a la conclusión de que la confianza en relación con estas instituciones estaba significativamente asociada no solo con algunos factores socio-demográficos (edad, educación y tamańo de la población) y con el apoyo al sistema (una medición de la legitimidad que los encuestados le asignan a su sistema político), sino también con la satisfacción con el desempeño del Gobierno nacional y con la satisfacción con los servicios proporcionados por los Gobiernos locales. 
En una dirección diferente, Manin et al. (1999) planteaban que buena parte de la explicación para la crisis de representación en esta región radicaba en las tremendas asimetrías de información existentes entre la clase política y los ciudadanos. Como consecuencia directa de ello, la clase política terminaba gozando de amplios márgenes de autonomía en relación con las decisiones de gobierno. Sin desconocer que estas asimetrías de información son algo típico en todo sistema de representación democrático, sostenían que esto era aún más grave en sociedades caracterizadas por altos niveles de pobreza y desigualdad, y en donde los gobiernos tienen menos incentivos para responder a las demandas de sus electores. Al final, y en el largo plazo, los ciudadanos llegan a sentirse traicionados por la clase política.

En este punto, es necesario destacar el que ha sido sin duda uno de los principales trabajos que se llevaron a cabo sobre la representación política en los países andinos (Bolivia, Ecuador, Colombia, Perú y Venezuela): el volumen editado por Scott Mainwaring, Ana María Bejarano y Eduardo Pizarro Leongómez, The Crisis of Democratic Representation in the Andes (Mainwaring et al. 2006). Una de las principales contribuciones de este trabajo es que, a diferencia de varios otros, ofrece un análisis empírico de este fenómeno en los países andinos. Para estos autores, la crisis de representación democrática en los países andinos se expresaba en una profunda insatisfacción con la democracia, los partidos y las legislaturas; es decir, con los principales agentes y los mecanismos de la representación democrática. Esta profunda insatisfacción es la que habría generado el surgimiento de outsiders políticos en estos países con claros discursos antisistema.

De manera más específica, estos autores proponían no solo una revisión del concepto de representación política o democrática, sino que también justifican una estrategia para su operacionalización. En esa dirección, afirman que la representación democrática se mide tanto en indicadores subjetivos (confianza en partidos, legislaturas y políticos) como en el comportamiento político de los ciudadanos (participación y preferencias electorales). Por lo tanto, los autores hablan de una crisis de representación democrática cuando en el nivel subjetivo los ciudadanos — en realidad una clara mayoría de ellos_ no confían o no perciben como legítimos a los agentes de las representación democrática; y cuando al nivel de comportamiento político, los ciudadanos optan por apoyar a candidatos o partidos antisistema, optan por apoyar nuevos partidos, cambian sus preferencias electorales con gran frecuencia o deciden no participar en las elecciones.

La información empírica presentada y analizada por los autores dejaba pocas dudas en relación a la existencia de una clara crisis de representación democrática 
en los países andinos en los años 2002 y 2003. En relación con la confianza en los partidos políticos y las legislaturas nacionales, los datos del Latinobarómetro mostraban que en los países andinos, a excepción de Venezuela, se había dado una disminución significativa si es que se comparaba el periodo 2002-2003 con el periodo 1996-1997. Igualmente, si se comparaba lo que estaba sucediendo a inicios del siglo XXI con ańos anteriores, se observaba en los países andinos un aumento importante de la volatilidad electoral, una mayor presencia de nuevos partidos en los resultados electorales, outsiders ganando elecciones o siendo ampliamente votados, y cierta disminución en la participación electoral (sobre todo en las elecciones parlamentarias).

Por último, Mainwaring et al. (2006) analizaban un conjunto de evidencia empírica relacionada con los niveles de representación programática existente en los países andinos. Ya sea que la representación programática se mida como la correspondencia entre la posición ideológica de los votantes (izquierdaderecha) y su elección partidaria, o se mida como la distancia entre la posición ideológica entre los votantes (izquierda-derecha) y la posición ideológica de los partidos, la evidencia apunta también a la existencia de una débil representación programática en los países andinos.

\subsection{Pendientes en la investigación sobre la representación política en los países andinos}

Una de las principales debilidades de la literatura sobre representación política en América Latina, y de manera particular en los países andinos, radica en haberse quedado demasiado enganchada con la constatación de una profunda y persistente brecha entre representados y representantes dentro de estos países. En este sentido, se hace necesario revisar críticamente lo que ha sido la agenda de investigación sobre este fenómeno para identificar vacíos y pensar en nuevas preguntas. En este sentido, el trabajo de Luna (2006) es particularmente útil como un primer balance sobre esta literatura.

Para Luna (2006: 7), durante los noventa, el estudio de la representación política en América Latina ha sido dominado por un paradigma procedimental influenciado sobre todo por las perspectivas de análisis institucionalistas que tienden a centrarse en las élites partidarias y sus interacciones en el marco de las instituciones formales que rigen cada sistema político. Sin desconocer la contribución que esta perspectiva de análisis ha hecho sobre las características «formales» de los regímenes políticos latinoamericanos, el principal problema es que ella ha terminado siendo demasiado "estrecha» para explicar las causas 
de los problemas de representación política que aquejan nuestra región (Luna 2006: 12). A modo de ejemplo, Luna sostiene que varios de los paradigmas en relación con la representación política se centran en analizar la estructuración y condicionantes de las mediaciones partidarias. Sin embargo, hoy en día los partidos políticos se encuentran muy debilitados en la región y enfrentan un déficit de legitimidad significativo. Por lo tanto, el análisis de la representación política vía partidos (así como de sus déficits) resulta insuficiente. Se propone, entonces, que se entienda la representación política en un sentido más amplio, incluyendo el análisis de los distintos tipos de vinculación (frecuentemente no partidaria ni programática) entre gobernantes y representados.

Por el contrario, entender mejor el actual déficit de representación política en nuestra región demandaría, en primer lugar, desplazar el foco analítico que ha predominado en la ciencia política en los noventa bajo el influjo de enfoques centrados en instituciones formales y élites políticas (oferta). En segundo lugar, demandaría también no reemplazarlo por completo por una perspectiva de análisis unilateralmente centrada en la sociedad civil (demanda), como la que suele caracterizar a mucha de la literatura reciente sobre movimientos sociales; entre varias razones porque estas experiencias de movilización y participación ciudadana o bien no logran constituirse en mecanismos de representación política institucionalizados y estables o, si lo hacen, no logran trascender ámbitos muy locales (Luna 2006: 29-30).

Dada esta situación, es impostergable la necesidad de desarrollar una nueva sociología política de la representación para intentar describir y explicar los distintos tipos de equilibrio existentes actualmente entre "oferta» $\mathrm{y}$ «demanda» de representación, en distintas sociedades latinoamericanas y entre diversos sectores sociales al interior de dichas sociedades. A su vez, los mecanismos causales específicos que crean y sostienen dichos equilibrios deben ser teorizados y abordados empíricamente mediante la incorporación explícita en el marco teórico de los cambios de matriz sociopolítica y económica constatados en la región durante las últimas décadas. Entre otras cosas, dichas transformaciones han polarizado y fragmentado las sociedades latinoamericanas; han modificado (en muchos casos reducido) la capacidad de acción y mediación del Estado, lo que a su vez ha generado un alto descontento social en relación con el desempeño de los Gobiernos y problemas de legitimidad para Estados y regímenes democráticos; han introducido cambios significativos en la manera cómo se relacionan — por un lado- electores y ciudadanos, y — por el otroorganizaciones políticas y autoridades (Luna 2006: 30). 
4. ¿QUÉ MUESTRA LA EVIDENCIA MÁS RECIENTE SOBRE LA REPRESENTACIÓN POLÍTICA Y SU CRISIS EN LOS PAÍSES ANDINOS?

Partiendo de la constatación de que pocos trabajos sobre la crisis de representación política, dentro y fuera de América Latina, se caracterizaban por combinar una discusión teórica con el análisis de evidencia empírica, resulta sumamente importante examinar hasta qué punto se mantiene o ha cambiado el panorama encontrado y analizado por Mainwaring et al. (2006). Una primera mirada a algunas de las variables consideradas por estos autores muestra cambios importantes en los años más recientes. Por ejemplo, los datos del Latinobarómetro revelan que de 2003 en adelante la confianza en la legislatura nacional ha experimentado un repunte altamente significativo en el caso de Venezuela y un repunte importante en los casos de Colombia, Bolivia y Ecuador (ver Gráfico 1). Una situación prácticamente idéntica se observa al examinar la confianza en los partidos políticos (ver Gráfico 2). Por lo tanto, existe alguna evidencia para sugerir que el tema de la representación política, por lo menos en Venezuela, Colombia, Bolivia y Ecuador, no solo habría experimentado un cambio importante en los últimos años, sino que además se trataría de un proceso de mejora o recuperación de la misma. Por lo menos desde el punto de vista de los ciudadanos.

\section{Gráfico 1. Confianza en la legislatura nacional (algo y mucha confianza)}

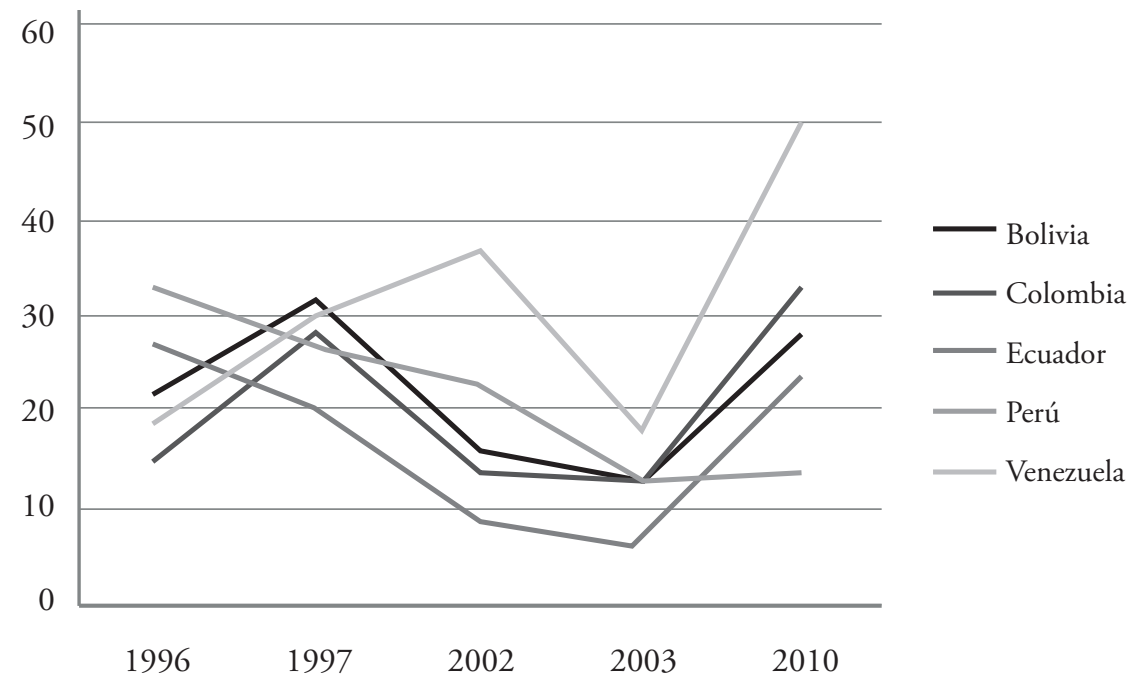

Fuente: Latinobarómetro

Elaboración propia. 


\section{Gráfico 2. Confianza en los partidos políticos (algo y mucha confianza)}

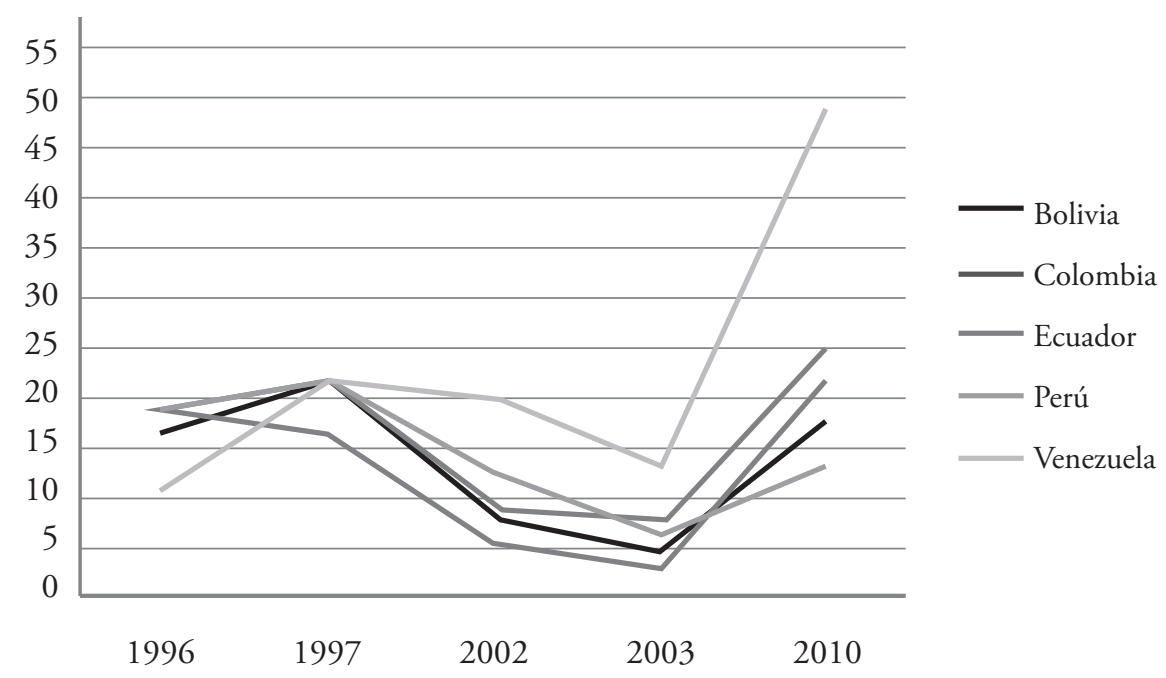

Fuente: Latinobarómetro

Elaboración propia.

A partir de los datos del Barómetro de las Américas para 2010, es posible teórica y metodológicamente- construir un índice del grado de representación política existente percibido por los ciudadanos de los países andinos (Bolivia, Ecuador, Colombia, Perú y Venezuela). Este índice está compuesto por las siguientes variables:

(1) Índice sobre el nivel de confianza en instituciones y cargos representativos (Congreso Nacional, Gobierno Nacional, partidos políticos y presidente elegido).

(2) Nivel de confianza en las elecciones.

(3) Percepción sobre el interés de las personas que gobiernan en lo que piensa la gente.

Al comparar los promedios nacionales para este índice de representación política, se observa que Bolivia y Colombia van por delante, seguidos por Venezuela y Ecuador; siendo Perú el país que registra el valor más bajo (ver Gráfico 3). Al tener en cuenta la significancia estadística de estas diferencias, tenemos que, considerando un intervalo de confianza del 95\%, los promedios de Bolivia y Colombia son efectivamente mayores en comparación al resto de países. Que en el caso de Ecuador y Venezuela, sus promedios nacionales no pueden ser considerados como fundamentalmente diferentes, pero que sí son 
superiores en comparación al promedio de Perú. Finalmente, el promedio de Perú es significativamente diferente y menor en comparación al resto de países (ver Tabla 1).

\section{Gráfico 3. Índice de representación política, 2010}

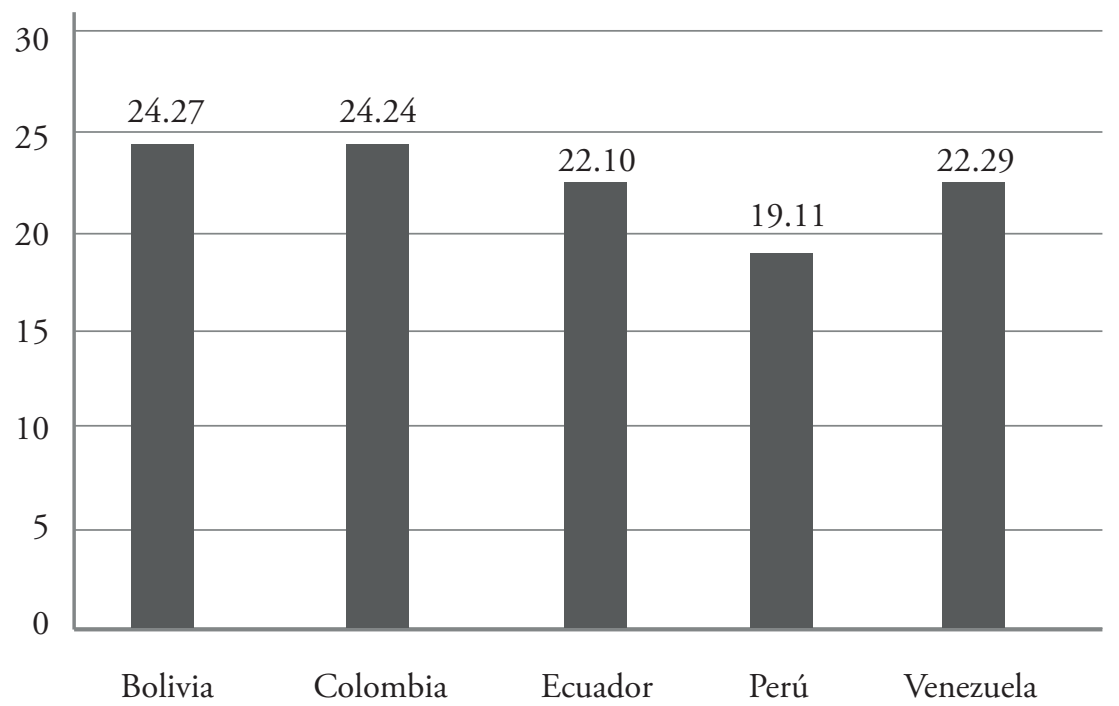

Fuente: LAPOP

Elaboración propia.

Tabla 1. Costos promedio del usuario final por TEU operado

\begin{tabular}{cccc} 
& & \multicolumn{2}{c}{ Intervalo de confianza al 95\% } \\
\cline { 3 - 4 } & Promedio & Límite inferior & Límite superior \\
\hline Bolivia & 24.27 & 24.01 & 24.52 \\
Colombia & 24.24 & 23.83 & 24.64 \\
Ecuador & 22.1 & 21.82 & 22.39 \\
Perú & 19.11 & 18.77 & 19.45 \\
Venezuela & 22.29 & 21.76 & 22.83 \\
\hline
\end{tabular}

Fuente: LAPOP

Elaboración propia.

A modo de síntesis de lo encontrado hasta este momento, se tiene que existe evidencia empírica que permite afirmar que en varios de los países andinos (Bolivia, Colombia, Venezuela y Ecuador) se ha dado un proceso de mejora y 
recuperación de los niveles de representación política a nivel de los ciudadanos. De igual modo, existe evidencia que permite sostener que el Perú es el único país donde se podría seguir hablando de una crisis o un déficit considerable en relación con la representación política. Ahora bien, antes de pasar a pensar cuál podría ser el significado de estos hallazgos, es posible llevar a cabo otro tipo de análisis que permita identificar cuáles son las principales determinantes de la percepción sobre la representación política que tienen los ciudadanos en estos países. Para ello, y haciendo uso de modelos de regresión lineal, a continuación se presentan y discuten los resultados por país. Dentro de estos modelos, la variable dependiente es el valor del índice de representación política y las variables explicativas son: (a) un proxy del nivel socioeconómico, (b) género, (c) edad, (d) número de años de educación formal, (e) ideología, (f) nivel de comprensión de asuntos políticos y (g) percepción sobre el rol del Estado (ver Anexo 1).

El análisis de los resultados de los cinco modelos considerados - uno por país - muestra un conjunto amplio de hallazgos que son altamente relevantes para la comprensión de la dinámica de la representación política en los países andinos. Para comenzar, existen algunas variables que de manera sistemática aparecen como determinantes estadísticamente significativas e importantes del nivel de representación política percibido por los entrevistados. En esta dirección, en todos los países andinos, en la medida que aumenta la autopercepción en relación con la capacidad de entender bien los asuntos políticos, aumenta también el nivel de representación política que se le reconoce al actual régimen político. De manera similar, en todos los países, al aumentar el nivel educativo de los entrevistados disminuye la percepción sobre el grado de representación política existente. Finalmente, vale la pena destacar también que en el caso de Bolivia, Ecuador y Perú, a medida que aumenta la edad de los entrevistados disminuye la percepción sobre el grado de representación política existente. Por lo tanto, esta evidencia permite afirmar que, en la región andina, los ciudadanos con mayores niveles de educación formal y los ciudadanos de mayor edad se sienten menos representados por sus gobiernos, gobernantes y por las instituciones y procedimientos de la democracia. Por el contrario, la sensación de que ser capaz de entender los asuntos políticos está vinculada a una visión mucho menos crítica o negativa del funcionamiento de la representación política (ver Tablas 2, 3, 4, 5, y 6). 
Tabla 2. Representación política en Bolivia, 2010 (Regresión lineal).

\begin{tabular}{cccc}
\hline & Coeficiente & Desv. Estándar & Significancia \\
\hline Proxy NSE & -0.300 & 0.182 & 0.100 \\
Género & -0.346 & 0.277 & 0.212 \\
Edad & $-0.038^{* * *}$ & 0.010 & 0.000 \\
Educación & $-0.339^{* * *}$ & 0.034 & 0.000 \\
Ideología & $-0.488^{* * *}$ & 0.072 & 0.000 \\
Comprensión asuntos públicos & $1.32^{* * *}$ & 0.101 & 0.000 \\
Rol del Estado & $0.251^{* * *}$ & 0.022 & 0.000 \\
\hline
\end{tabular}

$\mathrm{R}^{2}=0.226$

$* \mathrm{p}<0.05$

$* * \mathrm{p}<0.01$

**** $\mathrm{p}<0.001$

Fuente: LAPOP

Elaboración propia.

Tabla 3. Representación política en Colombia, 2010 (Regresión lineal).

\begin{tabular}{cccc}
\hline & Coeficiente & Desv. Estándar & Significancia \\
\hline Proxy NSE & -0.342 & 0.269 & 0.205 \\
Género & $1.366^{* * *}$ & 0.422 & 0.001 \\
Edad & -0.025 & 0.015 & 0.090 \\
Educación & $-0.38^{* * *}$ & 0.054 & 0.000 \\
Ideología & $0.86^{* * *}$ & 0.089 & 0.000 \\
Comprensión asuntos públicos & $0.819^{* * *}$ & 0.132 & 0.000 \\
Rol del Estado & $0.251^{* * *}$ & 0.022 & 0.000 \\
\hline
\end{tabular}

$\mathrm{R}^{2}=0.180$

$* \mathrm{p}<0.05$

${ }_{* *}^{* *}<0.01$

*** $\mathrm{p}<0.001$

Fuente: LAPOP

Elaboración propia. 
Tabla 4. Representación política en Ecuador, 2010 (Regresión lineal).

\begin{tabular}{cccc}
\hline & Coeficiente & Desv. Estándar & Significancia \\
\hline Proxy NSE & $-0.698^{* * *}$ & 0.21 & 0.001 \\
Género & -0.294 & 0.345 & 0.394 \\
Edad & $-0.036^{* *}$ & 0.011 & 0.002 \\
Educación & $-0.348^{* * *}$ & 0.046 & 0.000 \\
Ideología & $-0.168^{*}$ & 0.073 & 0.021 \\
Comprensión asuntos públicos & $1.088^{* * *}$ & 0.107 & 0.000 \\
Rol del Estado & $0.178^{* * *}$ & 0.028 & 0.000 \\
\hline
\end{tabular}

$\mathrm{R}^{2}=0.104$

${ }^{*} \mathrm{p}<0.05$

$* * \mathrm{p}<0.01$

*** $\mathrm{p}<0.001$

Fuente: LAPOP

Elaboración propia.

Tabla 5. Representación política en Perú, 2010 (Regresión lineal).

\begin{tabular}{cccc}
\hline & Coeficiente & Desv. Estándar & Significancia \\
\hline Proxy NSE & $-0.729^{* *}$ & -0.084 & 0.004 \\
Género & -0.181 & 0.364 & 0.620 \\
Edad & $-0.048^{* * *}$ & 0.012 & 0.000 \\
Educación & $-0.169^{* * *}$ & 0.052 & 0.001 \\
Ideología & $0.489^{* * *}$ & 0.090 & 0.000 \\
Comprensión asuntos públicos & $0.974^{* * *}$ & 0.124 & 0.000 \\
Rol del Estado & -0.042 & 0.027 & 0.116 \\
\hline
\end{tabular}

$\mathrm{R}^{2}=0.226$

$* \mathrm{p}<0.05$

${ }_{* *} \mathrm{p}<0.01$

*** $\mathrm{p}<0.001$

Fuente: LAPOP

Elaboración propia. 
Tabla 6. Representación política en Venezuela, 2010 (Regresión lineal).

\begin{tabular}{cccc}
\hline & Coeficiente & Desv. Estándar & Significancia \\
\hline Proxy NSE & $-2.223^{* * *}$ & 0.347 & 0.000 \\
Género & -0.930 & 0.534 & 0.082 \\
Edad & -0.002 & 0.019 & 0.929 \\
Educación & $-0.353^{* * *}$ & 0.077 & 0.000 \\
Ideología & $-1.066^{* * *}$ & 0.112 & 0.000 \\
Comprensión asuntos públicos & $1.082^{* * *}$ & 0.153 & 0.000 \\
Rol del Estado & 0.012 & 0.037 & 0.739 \\
\hline
\end{tabular}

$\mathrm{R}^{2}=0.226$

${ }^{*} \mathrm{p}<0.05$

${ }^{* *} \mathrm{p}<0.01$

${ }^{* * *} \mathrm{p}<0.001$

Fuente: LAPOP

Elaboración propia.

Con relación a las principales diferencias y semejanzas entre países, los resultados son igualmente reveladores. En primer lugar, Bolivia, Ecuador y Venezuela comparten un conjunto bastante amplio de determinantes significativas de la representación política. Además de lo ya mencionado sobre el impacto de nivel educativo, la autopercepción sobre la capacidad que se posee para entender los asuntos políticos y la edad; en estos tres países, la ideología de los entrevistados aparece como una determinante importante y significativa de la representación política. Específicamente, en Bolivia, Ecuador y Venezuela los individuos que se ubican más a la derecha del espectro político son quienes se muestran más escépticos en relación con el nivel de representación política existente en sus países en la actualidad. En el caso de Bolivia y Ecuador, la preferencia por una mayor intervención del Estado en la economía y en la sociedad aparece significativamente asociada a mayores niveles en la variable representación política. Asimismo, en el caso de Ecuador y Venezuela, las personas que pertenecerían a los niveles socioeconómicos más bajos — aquellas que tienen mayores dificultades para cubrir sus necesidades básicas — aparecen como más críticas o desconfiadas en relación con el nivel de representación política existente en sus países. En conjunto, estos hallazgos revelan que los países andinos con gobiernos de izquierda (Levitsky y Roberts 2011, Weyland et al. 2010, Cameron y Hershberg 2010) y, en particular, los actuales «gobiernos populista radicales» (De la Torre 2009) comparten una dinámica muy similar con relación a lo que viene sucediendo en torno al grado en que sus ciudadanos se sienten representados por sus gobiernos, gobernantes e instituciones. 
En un claro contraste con lo que se observa para los países andinos con gobiernos que se ubican en la izquierda, Colombia y Perú muestran una situación política diferente. En estos dos países, el efecto de la variable ideología sobre la representación política sigue siendo significativo; sin embargo, el signo de su efecto es contrario. De este modo, aquí son las personas que se ubican más a la derecha del espectro político quienes se sienten más cercanas o representadas por sus gobiernos, gobernantes e instituciones. Finalmente, un aspecto del análisis que no se debe pasar por alto es el efecto que la variable proxy para el nivel socioeconómico de los entrevistados en tres de estos países andinos (Ecuador, Venezuela y Perú). En estos tres casos, ser pobre o tener dificultades para satisfacer las necesidades básicas tiene un efecto significativo negativo sobre la representación política. Esto último no deja de ser particularmente revelador porque aun en aquellos países donde la identificación con los gobiernos de izquierda y sus políticas de intervención económica se asocian a una mejor percepción sobre el nivel de representación política existente, los pobres o más necesitados no comparten esa percepción positiva.

\section{Conclusiones}

A diferencia de lo que sucedía en los países andinos a comienzos de este siglo, en la actualidad es muy difícil sostener que existe una crisis generalizada de representación política en los regímenes democráticos de esta región. Específicamente, para el caso de Bolivia, Ecuador y Venezuela, una serie de variables e indicadores relacionados con el concepto de representación política muestran no solo cambios importantes, sino también una clara mejora o recuperación. Por el contrario, solo en el caso peruano hay claramente una continuidad de la situación crítica o deficitaria en relación con las percepciones que tienen los ciudadanos sobre el grado de representación política que encuentran en sus gobiernos, autoridades e instituciones. A partir de este hallazgo general, es posible avanzar algunos otros comentarios.

Si bien es cierto que dentro de América del Sur, los países andinos han tendido a mostrar las mayores limitaciones en cuanto a la calidad de sus regímenes democráticos, la evidencia aquí presentada revela que es posible que se dé una mejora significativa de la percepción que tienen los ciudadanos sobre el grado en que sus gobiernos, gobernantes e instituciones los representan; o por lo menos en las condiciones que harían posible una representación política más efectiva (la confianza en las instituciones políticas y la confianza en los procesos electorales). No menos significativo es el hecho de que estas 
recuperaciones o mejoras en la representación política se hayan concentrado en los países que han girado hacia la izquierda en los últimos años (Venezuela, Ecuador y Bolivia). Y que estén completamente ausentes en el caso peruano, en donde desde la década de los noventa del siglo pasado los diferentes Gobiernos han tendido a mantener lo que fueron las principales políticas asociadas con las reformas neoliberales (es decir, promover la inversión privada en la economía y reducir o evitar la intervención del Estado). Lo que se observa en el caso colombiano, muestra que es viable una tercera posibilidad. Que la mejora de la representación política se dé sin que sea necesario que la izquierda llegue al gobierno.

Por lo tanto, a la fecha, con relación a la dinámica de la representación política, lo más seguro es afirmar que hay una relación entre gobiernos de izquierda y una mejora de la percepción ciudadana sobre el grado de la representación política. Sin embargo, habría que reconocer también que la existencia de un gobierno de izquierda no es una condición necesaria para esta mejora. Dadas las similitudes entre el caso peruano y el colombiano (léase, la ausencia de gobiernos de izquierda o de un régimen populista de izquierda), queda pendiente entender mejor cómo es que las condiciones actuales en esos países son tan diferentes en cuanto a lo que viene sucediendo con las percepciones de los ciudadanos sobre el grado o la calidad de la representación política de sus regímenes democráticos.

Una mención especial merece el hecho de que en varios países andinos (Ecuador, Venezuela y Perú) la variable proxy del nivel socioeconómico de los entrevistados tenga un impacto significativo sobre la percepción en torno a la representación política que ofrecen gobiernos y autoridades elegidas. Específicamente, en este grupo de países, cuanto más precaria es la situación de los entrevistados (léase, cuando los ingresos del hogar no alcanzan y, por lo tanto, se tienen algunas o muchas dificultades para cubrir las necesidades básicas), menor es la sensación de estar políticamente representado. Y esto se observa incluso en los países donde ha habido una recuperación en las percepciones sobre representación política en buena cuenta a partir de la llegada al poder de líderes y organizaciones políticas de izquierda. Dicho de otro modo, no parece ser el caso que a la vanguardia de quienes se sienten mejor representados en la actualidad se encuentren sobre todo los más pobres.

Teniendo en cuenta las implicancias políticas de estos hallazgos, y reconociendo la naturaleza particular, ambigua y contradictoria de los regímenes populistas de izquierda en los países andinos (De la Torre 2008, 2009; Panizza 2008; Roberts 2008; Weyland 2001), no llega a ser del todo una sorpresa que 
se haya dado una mejora o una recuperación de la representación política en Venezuela, Ecuador y Bolivia. Lo que sí debe llamar a mayor reflexión es el tipo de relación que estaría existiendo entre — por un lado- una sensación de mayor cercanía de los ciudadanos con su autoridades y Gobierno y — por otro lado- gobiernos y liderazgos políticos que han sido calificados como populistas, plebiscitarios, personalistas o altamente ambivalentes en relación con la democracia y su institucionalidad.

Al comienzo de este texto se hacía alusión a la existencia de una serie de paradojas dentro de la situación política de los países latinoamericanos. Lo observado aquí en relación con la dinámica de la representación política de los países andinos parece ser un nuevo ejemplo de esta naturaleza paradójica. Mainwaring et al. (2006) sostenían que la crisis de la representación democrática de los países andinos había abierto la puerta a formas de representación plebiscitarias y personalistas. Asimismo, afirmaban que estas «nuevas» formas de representación política fácilmente podían poner en riesgo los principios centrales de la democracia. Sin entrar a la discusión sobre cuánta razón terminaron teniendo estos autores, es un hecho que cuando se observa la evolución de los mismos o muy similares indicadores que se usaban para dar cuenta de la crisis de representación política en Bolivia, Ecuador y Venezuela, es evidente que existe una conexión entre estas formas de representación más plebiscitarias y populistas, y una mejora de la percepción ciudadana en relación con el grado de representación política que gozan en la actualidad.

Adicionalmente, con relación al estudio y la investigación sobre la naturaleza y la dinámica de la representación política, lo planteado hasta aquí nos anima a plantear algunos comentarios adicionales. En primer lugar, la importancia que tiene combinar la discusión más teórica y conceptual que se ha venido, y se viene, produciendo en torno a la representación política con algún tipo de evidencia empírica que permita validar y perfilar nuestras hipótesis y afirmaciones. Esto es aún más importante en un contexto donde la evidencia empírica es todavía muy escasa y perfectible. En esta dirección, habría mucho que aprender de quienes han venido trabajando el tema de la legitimidad política y del apoyo a la democracia en América Latina (Booth y Seligson 2009). Sin duda, una de las ventajas de contar con más investigaciones empíricas sobre la naturaleza y la dinámica de la representación política en los países andinos es poder tener la oportunidad también para llevar a cabo una revisión de los paradigmas y las perspectivas teóricas que han sido y son comúnmente utilizadas cuando se discuten sobre estos temas. En esta dirección, es posible mejorar nuestra 
comprensión del tipo de representación política realmente existente y posible en estos países.

Finalmente, pensando en algunos temas que quedan pendientes. En general, queda pendiente una discusión sobre la relación existente entre representación política, liderazgos políticos y organizaciones políticas. En este sentido, los países andinos donde ha repuntado la representación política son países con gobiernos altamente personalistas (Hugo Chávez, Rafael Correa y Evo Morales) y en donde el tipo de liderazgo político que se está ejerciendo no parece conducir a ningún proceso significativo de consolidación o institucionalización de un partido o de una organización política. Esto tiene sin duda varias consecuencias.

Para comenzar, la combinación de (a) gobiernos fuertemente personalizados, carentes de una organización partidaria importante y con muchas dificultades para elegir a sucesores medianamente carismáticos y (b) mejoras en las percepciones de los gobernados sobre la capacidad de representación política de sus gobiernos, nos lleva a pensar que no es improbable que estemos frente a procesos que no necesariamente van a durar mucho tiempo. En este sentido, lo que estaríamos observando es un momento de recuperación de la sensación de sentirse políticamente representado y no el inicio de una nueva etapa o el surgimiento de un nuevo tipo de relación entre gobernantes, gobierno y gobernados; y en donde, por ejemplo, sean las instituciones políticas las que finalmente recuperen o ganen algo de legitimidad política. En cualquier caso, no debe pasarse por alto que esta recuperación de la representación política se habría originado a partir de la combinación de elementos de democracia representativa (por ejemplo, gobierno elegidos y reelegidos por la ciudadanía) con otros elementos que, a falta de mejor nombre, podemos calificar como populistas. Los mismos que incluyen un alto grado de personalización del liderazgo político presidencial e iniciativas que muchas veces están al límite con relación al orden constitucional existente y el estado de derecho.

Pensando específicamente en el caso peruano, habría que tener en cuenta que los datos aquí analizados no cubren lo que ha venido sucediendo después de 2010. En ese sentido, queda pendiente indagar qué tanto han cambiado, en el contexto de un nuevo gobierno, las percepciones y evaluaciones de los peruanos sobre la capacidad de la democracia, de los gobernantes elegidos, de las autoridades y de las instituciones de gobierno en general, para representarlos políticamente. Dado lo que ha sido el devenir del gobierno de Ollanta Humala a la fecha, podemos esperar que lo que se encuentre sea una mezcla de, por lo menos, tantas continuidades como cambios. 


\section{Bibliografía}

Booth, John A. y Mitchell A. Seligson (2009). The Legitimacy Puzzle in Latin America. New York: Cambridge University Press. https:/doi.org/10.1017/CBO9780511818431

Cameron, Maxwell y Eric Hershberg (2010). Latin America's left turn: Politics, policies, and trajectories of change. Boulder: Lynne Rienner Publishers.

Colomer, Josep y Luis Escatel (2005). «La dimensión izquierda-derecha en América Latina». Desarrollo Económico. 45(177), pp. 123-136.

https:/doi.org/10.2307/3655894

Corral, Margarita (2010). «Partidos políticos y representación en América Latina». Perspectivas desde el Barómetro de las Américas. Nro. 36.

De la Torre, Carlos (2009). «Populismo Radical y Democracia en los Andes». Journal of Democracy en Español. Nro. 1, pp. 24-37.

De la Torre, Carlos. (2008). «Populismo, ciudadanía y Estado de derecho». En De la Torre, Carlos y Enrique Peruzzotti (eds.). El retorno del pueblo. Populismo y nuevas democracias en América Latina. Quito: FLACSO Ecuador.

Hagopian, Frances (1998). «Democracy and Political Representation in Latin America in the 1990s: Pause, Reorganization, or Decline?». En Agüero, Felipe y Jeffrey Stark (eds.). Fault Lines of Democracy in Post-Transitional Latin America. Boulder: North-South Center Press, pp. 99-143.

Huber, Evelyne y John Stephens (1999). "The Bourgeoisie and Democracy: Historical and Contemporary Perspectives». Social Research. No. 66(3), pp. 759-788. http://dx.doi.org/10.1007/978-3-322-81013-7_15

Kitschelt, Herbert (2000). «Linkages between citizens and politicians in democratic polities». Comparative Political Studies. No. 33(6/7), pp. 845-879. https:/doi.org/10.1177/001041400003300607

Lechner, Norbert (1998). «The Transformation of Politics». En Agüero, Felipe y Jeffrey Stark (eds.). Fault Lines of Democracy in Post-Transition Latin America. Miami: North-South Center Press, pp. 21-40.

Levitsky, Steven y Kenneth Roberts (2011). The resurgence of Latin America left. Baltimore: The Johns Hopkins University Press.

Luna, Juan Pablo (2006). Representación politica en América Latina: El estado de la cuestión. Lima: Departamento de Ciencias Sociales de la Pontificia Universidad Católica del Perú.

Mainwaring, Scott (2008). "Deficiencias estatales, competencia entre partidos y confianza en la representación democrática de la región andina». En Tanaka, Martín (ed.). La nueva coyuntura crítica en los países andinos. Lima: IDEA-IEP.

Mainwaring, Scott; Ana María Bejarano y Eduardo Pizarro Leóngomez (2006). «The crisis of democratic representation in the Andes: An overview». En Mainwaring Scott, Ana María Bejarano y Eduardo Pizarro Leóngomez (eds.). The crisis of democratic representation in the Andes. Stanford: Stanford University Press. https:/doi.org/10.11126/stanford/9780804752787.001.0001

Manin, Bernard (1992). «Metamorfosis de la representación». En Dos Santos, Mario R. (coordinador). ¿Qué queda de la representación politica? Caracas: Editorial Nueva Sociedad, pp. 9-40.

Manin, Bernard, Adam Przeworski y Susan Stokes (1999). «Elections and representation». En Przeworski, Adam, Susan Stokes y Bernard Manin (eds.). Democracy, accountability and representation. New York: Cambridge University Press.

NegrettoE, Gabriel (2009 [2004]). «Paradojas de la reforma constitucional en América Latina». Journal of Democracy en Español. Nro. 1, pp. 38-54. 
O’Donnell, Guillermo (2007). "The perpetual crisis of democracy». Journal of Democracy. No. 18(1), pp. 5-11. https:/doi.org/10.1353/jod.2007.0012

Pachano, Simón (2012). «Calidad de la democracia en los países andinos». En Murakami, Yusuke (ed.). Dinámica política-económica de los países andinos. Lima: CIAS-IEP.

Panizza, Francisco (2008). «Fisuras entre populismo y democracia en América Latina». En De la Torre, Carlos y Enrique Peruzzotti (eds.). El retorno del pueblo. Populismo y nuevas democracias en América Latina. Quito: FLACSO Ecuador.

Pitkin, Hanna (1985). El concepto de representación. Madrid: Centro de Estudios Constitucionales.

PNUD (2010). Nuestra Democracia. México D.F.: Fondo de Cultura Económica.

Powell, G. Bingham Jr. (2004). «Political Representation in Comparative Politics». Annual Review of Political Science. No. 7, pp. 273-296.

https:/doi.org/10.1146/annurev.polisci.7.012003.104815

Przeworski, Adam (2010). Democracy and the limits of self-government. New York: Cambridge University Press. https:/doi.org/10.1017/CBO9780511778490

Roberts, Kenneth (2008). «El resurgimiento del populismo latinoamericano». En De la Torre, Carlos y Enrique Peruzzotti (eds.). El retorno del pueblo. Populismo y nuevas democracias es América Latina. Quito: FLACSO Ecuador.

Roberts, Kenneth (2002). «Social Inequalities without Class Cleavages in Latin America’s Neoliberal Era». Studies in Comparative Development. No. 36(4), pp. 3-33. https:/doi.org/10.1007/BF02686331

Sartori, Giovanni (1999). «En defensa de la representación política». Claves de Razón Práctica. Nro. 91, pp. 2-6.

Taylor-Robinson, Michelle (2010). Do the poor count? Democratic institutions and accountability in a context of poverty. University Park: The Pennsylvania State University Press.

Weyland, Kurt (2005). «The Growing Sustainability of Brazil's Low-Quality Democracy». En Hagopian, Frances y Scott Mainwaring (eds.). The Third Wave of Democratization in Latin America. Advances and Setbacks. Cambridge: Cambridge University Press.

Weyland, Kurt. 2001. "Clarifying a contested concept: Populism in the study of Latin American politics». Comparative Politics. No. 34(1), pp. 1-22.

https:/doi.org/10.2307/422412

Weyland, Kurt, Raúl Madrid y Wendy Hunter (2010). Leftist governments in Latin America: Successes and shortcomings. New York: Cambridge University Press.

http://dx.doi.org/10.1017/cbo9780511778742 


\section{ANEXO: SOBRE LA CONSTRUCCIÓN DE ALGUNAS DE LAS VARIABLES UTILIZADAS EN EL ANÁLISIS}

\section{Variable dependiente \\ Representación politica}

La variable representación politica es el resultado de la construcción de un índice que combina (a) las respuestas a cuatro preguntas en torno al nivel de confianza que se le otorga a diferentes instituciones y cargos representativos (Congreso Nacional, Gobierno Nacional, partidos políticos y presidente elegido), (b) la respuesta a una pregunta sobre el grado de confianza que se tiene en relación con las elecciones y (c) la respuesta a una pregunta sobre el nivel de acuerdo o desacuerdo con relación a la siguiente afirmación: A los que gobiernan el país les interesa lo que piense la gente como yo. En todos estos casos las alternativas de respuesta iban de 01 a 07 , donde 01 significaba nada de confianza o muy en desacuerdo con la afirmación ofrecida. Y donde 07 significaba mucha confianza o muy de acuerdo con la afirmación ofrecida. Dado que esta variable fue construida como un índice compuesto tradicional, el puntaje para cada persona entrevistada es el producto de una sumatoria simple de todas sus respuestas y por lo tanto tienen 06 como valor mínimo y 40 como valor máximo. Los valores que se obtienen al calcular el Coeficiente Alfa de Cronbach de este índice para cada uno de los países (ver Tabla 7) confirman que es posible usarlo como una medida resumen confiable para la variable representación politica.

Tabla 7. Coeficientes Alfa de Cronbach por país calculado para las variables que conforman el índice de representación política, 2010.

\begin{tabular}{cc}
\hline & Coeficiente Alfa de Cronbach \\
\hline Bolivia & 0.807 \\
Ecuador & 0.815 \\
Colombia & 0.776 \\
Perú & 0.786 \\
Venezuela & 0.891 \\
\hline
\end{tabular}

Fuente: LAPOP

Elaboración propia. 


\section{Variables explicativas}

Nivel socioeconómico (proxy)

Para el cálculo del nivel socioeconómico de los entrevistados se utilizó una variable proxy. Los valores de esta variable proxy se establecieron a partir de las respuestas a la siguiente pregunta: El salario o sueldo que usted recibe y el total del ingreso de su hogar, les alcanza bien, pueden ahorrar (1), les alcanza justo, sin grandes dificultades (2), no les alcanza, tienen dificultades (3), no les alcanza, tienen grandes dificultades (4).

\section{Ideología}

Para el cálculo de la variable ideología, para cada uno de los entrevistados se utilizó la siguiente pregunta: Hoy en día mucha gente, cuando habla conversa de tendencias politicas, habla de gente que simpatiza más con la izquierda o con la derecha, ¿dónde se encontraría usted en esta escala? (donde 01 representa izquierda y 10 derecha).

\section{Comprensión de los asuntos politicos}

La variable sobre el nivel de comprensión que los entrevistados creen tener sobre los asuntos públicos se origina a partir de una pregunta sobre el nivel de acuerdo o desacuerdo en relación con la siguiente afirmación: Usted siente que entiende bien los asuntos políticos más importantes del país. Las categorías de respuesta iban de 01 a 07 , donde 01 significaba muy en desacuerdo y 07 muy de acuerdo.

\section{Rol del Estado}

La variable rol del Estado consiste en un índice que combina el nivel de acuerdo de los entrevistados en relación con diferentes afirmaciones sobre el rol del Estado: (a) El Estado peruano, en lugar del sector privado, debería ser el dueño de las empresas e industrias más importantes del país, (b) el Estado peruano, más que los individuos, debería ser el principal responsable de asegurar el bienestar de la gente, (c) el Estado peruano, más que la empresa privada, debería ser el principal responsable de crear empleos, (d) el Estado peruano debe implementar políticas firmes para reducir la desigualdad de ingresos entre ricos y pobres, (e) el Estado peruano, más que el sector privado, debería ser el principal responsable de proveer las pensiones de jubilación y (f) el Estado peruano, más que el sector privado, debería ser el principal responsable de proveer los servicios de salud. En todos estos casos, las alternativas de respuesta van de 01 a 07, donde 01 representa muy en desacuerdo, y 07 muy de acuerdo. Dado que se trata también de un índice compuesto simple, el puntaje mínimo 
para esta variable es 06 y el puntaje máximo es 42 . Al igual que con el índice de representación política, los valores del Coeficiente Alfa de Cronbach (ver Tabla 8) confirman que esta variable es un resumen confiable de las actitudes personales en relación con lo que se cree debería ser el rol del Estado.

Tabla 8. Coeficientes Alfa de Cronbach por país calculado para las variables que conforman el índice sobre el rol del Estado, 2010.

\begin{tabular}{cc}
\hline & Coeficiente Alfa de Cronbach \\
\hline Bolivia & 0.861 \\
Ecuador & 0.770 \\
Colombia & 0.717 \\
Perú & 0.846 \\
Venezuela & 0.778 \\
\hline
\end{tabular}

Fuente: LAPOP

Elaboración propia. 